\title{
Can Mother's Depression Affect Infant's Development?
}

\author{
Narges Mohamadi Parsa (iD) ${ }^{1,}$, Abbas Mohamadi (iD ${ }^{2}$ and Fatemeh Einabadi (iD) ${ }^{3}$ \\ ${ }^{1}$ Clinical Research Development Unit of Beasat Hospital, Hamadan University of Medical Sciences, Hamadan, Iran \\ ${ }^{2}$ Department of Community Medicine, Hamedan University of Medical Science, Hamedan, Iran \\ ${ }^{3}$ Family Health Unit of the Health Center of Hamedan, Hamedan University of Medical Science, Iran \\ "Corresponding author: Clinical Research Development Unit of Beasat Hospital, Hamadan University of Medical Sciences, Hamadan, Iran. Email: nmohamadi646@gmail.com
}

Received 2021 March 10; Revised 2021 June 09; Accepted 2021 September 02.

\begin{abstract}
Background: The mental state of the mother is one of the factors influencing the development of infants. Besides, the quality of the child's relationship with her/his parent is very important in childhood development.

Objectives: This study aimed at investigating the relationship between the mother's depression and developmental disorders in infants.

Methods: This cross-sectional study utilized a sample size of 311 subjects. The study population included all infants and their mothers who were referred to health centers of the city of Hamadan, Iran, to receive the usual one-year care. Mothers' depression was assessed with the second edition of the Beck Depression Inventory, and children's developmental disabilities were assessed with one-year Ages and Stages Questionnaire.

Results: The mean age of mothers in this study was $29.7 \pm 5.6$. The prevalence of developmental disorders in infants was $3.5 \%$. This study showed that mothers' depression had no significant relationship with any of the developmental domains in infants. None of the developmental domains in infants were related to the mother's occupation and education. However, the gross motor skills (Pvalue: 0.007 ) and problem-solving skills (P-value: 0.031) were significantly related to the socioeconomic level, and communication (P-value: 0.034), and personal-social skills (P-value: 0.026) of the infant were directly related to the mother's age.

Conclusions: Mother's depression is not related to the infant's developmental disorders. There is a relationship between the socioeconomic level of the family and gross motor and problem-solving skills of the infant. The mother's age is directly related to communication and personal-social skills of the infant.
\end{abstract}

Keywords: Infant, Developmental Disability, Mother's Depression

\section{Background}

The development includes the abilities that human beings acquire in physical, mental, linguistic, and social aspects during their lifetime. These factors are influenced by heredity, environment, nutrition, and social stimuli (1), and the term developmental delay is used for children who do not have the necessary abilities and skills compared to healthy children of the same age (2). Overall, an estimated 200 million children under the age of five suffer from developmental disabilities worldwide (3). On average, about 15 to $18 \%$ of children in different communities suffer from speech, learning, and emotional-behavioral disabilities, and $15 \%$ of children have serious psychosocial problems (4). The prevalence of developmental disabilities in several cities of Iran is reported between 18.7 and $19.8 \%$ (5). However, the root cause of developmental delay is unclear, and no specific cause can be identified as the main cause of this problem (6). Nevertheless, since human de- velopment is the result of a dynamic and continuous interaction of biological and acquired factors, numerous hereditary and environmental factors are involved (7).

In this situation, the family and its health status have an important impact on the development of the child in the first years of life, so any physical or mental problems, violence, depression, and chronic diseases in the mother can harm the child (8). Mother's depression can theoretically be considered a before-birth factor because studies have shown the effect of a mother's depression and anxiety during pregnancy on fetal neuromotor development (9). It can also be an after-birth factor because the optimal and healthy growth of children in all dimensions depends on the effective and desirable relationship between parents and children, and the quality of the parent-child relationship is very important for the growth and development during childhood (10). 


\section{Objectives}

In this study, we investigated one of the dimensions of the mother-child relationship, ie, the mother's depression, and its effect on developmental disabilities in one-year-old children (infants).

\section{Methods}

The study population of this cross-sectional study included all infants and their mothers who were referred to the health centers of the city of Hamadan, Iran, to receive the usual one-year care. A two-stage cluster sampling method was utilized. To eliminate the socioeconomic status of the family as a confounding variable, the first clusters were selected from the health centers in three different socioeconomic areas of the city of Hamadan, and in the next step, a convenience sample was taken from each cluster. To calculate the sample size, we used the " $r$ " value of 0.29 , according to the Black study (11), and considered $\alpha$ $=0.01$ and $\beta=0.01$; thus, about 300 subjects entered the study.

Inclusion criteria included each infant who was referred to health centers in Hamadan for health care, and exclusion criteria were physical or mental problems that could affect the child's developmental process, such as cerebral palsy and metabolic disorders like phenylketonuria.

For those who entered our study after obtaining oral informed consent, the mothers filled out the Ages \& Stages Questionnaire (ASQ) themselves in health centers and gave it back to our colleagues. The second edition of the Beck Depression Inventory (BDI-) was filled out by our colleague as a questionnaire to examine the mother's depression in the health center. Also, the questioner obtained mothers' demographic information. All the questionnaires were anonymous. Mothers' demographic data were collected using a researcher-made questionnaire, and the place of residence was used as the socioeconomic level index.

The Beck Depression Inventory (BDI-) contains 21 items and is one of the most appropriate tools for reflecting depression, which examines three groups of emotional, cognitive, and physical symptoms of depression. The inventory has different levels: Scores 0 to 13 show no or least depression, scores 14 to 19 show mild depression, scores 20 to 28 indicate moderate depression, and scores 29 to 63 show severe depression. In this study, people who received severe and very severe depression scores based on the BDI-II were regarded as depressed. The validity and reliability of the BDI-II in the Iranian population were assessed. Its Cronbach's alpha was 78\%, and the validity of the retest was $73 \%$ after two weeks (12).

The prevalence of developmental disabilities in this study was assessed using the ASQ. The ASQ is a relatively simple questionnaire that allows people with primary education to answer correctly. This test has clear and simple language; next to a large number of questions, simple images have been placed that increase the clarity of the questions; thus, it makes the ASQ applicable and easy to use (13). Pediatric residents have reported that the ASQ is the preferred screening instrument for developmental delay (14). This questionnaire contains 30 questions about the child's development and screens five domains: Communication, gross motor, fine motor, problem-solving, and personal-social skills. The cut-off point of the ASQ is considered to be two standard deviations lower than the average of each domain in Iranian children. Therefore, the cut-off point is 20.4 in the domain of communication skills, 21.5 in gross motor skills, 34.6 in fine motor skills, 33.7 in problemsolving skills, and 18.3 in personal-social skills (15).

Maternal depression and her employment were considered two-state nominal variables, and the independent $t$-test was used to test their relationships with different domains of developmental disorder. The socioeconomic status and maternal education were considered ordinal variables, and due to the existence of outlier data, based on the nature of the ASQ scores, the Kruskal-Wallis test was used to measure their relationship with different domains of developmental disorder. We used the Pearson correlation test to assess the relationship between mothers' age and developmental disorder. All calculations were done using SPSS 16 software.

\section{Results}

The mean age of mothers participating in this study was $29.7 \pm 5.6$ years. Besides, $33.8 \%$ of them had high school education, $32.2 \%$ high school diploma, and 34\% university education from technical diploma to Ph.D. Also, 13\% were working mothers and the rest of them were homemakers. According to the BDI-, the prevalence of severe and very severe depression in mothers was $20.2 \%$ (12.2\% severe and $8 \%$ very severe).

We counted the cases that had problems in more than one area only once. Thus, the overall prevalence of developmental disorders was 3.5\%. The prevalence of developmental disorders in infants was $0.3 \%$ in the communication domain, $2.3 \%$ in gross motor skills, $0.6 \%$ in fine motor skills, 
$0.3 \%$ in problem-solving skills, and $0.6 \%$ in personal-social skills.

As shown in Table 1, maternal depression was not related to any of the developmental domains in infants. Besides, the mother's depression was not related to the family socioeconomic status (P-value: 0.179), her employment status (P-value: 0.359), and her education level(P-value: 0.129). None of the domains of development were related to the mother's employment and education. However, gross motor skills (P-value: 0.007) and problem-solving skills (Pvalue: 0.031$)$ were directly related to the socioeconomic status. Communication (P-value: 0.034) and personalsocial skills (P-value: 0.026 ) were directly related to the mother's age.

\section{Discussion}

This study aimed at evaluating the relationship between the mother's depression and developmental disabilities in infants. The prevalence of moderate and severe depression was 20.2 and $8 \%$ among mothers of infants, respectively. The prevalence of depression varies greatly in different studies and depends on the measurement tool. Among the studies that used the BDI-II, Kaviyani's study estimated that the prevalence of depression in Tehran (the capital city of Iran) is $6.8 \%$ (16), and Modabarnia reported that the prevalence of minor and major depression in Rasht, Guilan province, was 5 and 1\% respectively (17). Also, the results of a meta-analysis in Iran indicated that the point prevalence of major depression in Iran is $4.1 \%$ (4.8\% in women and $2.3 \%$ in men), which is lower than the WHO global estimation for 2015(4.4\%)(18). This rate is lower than in countries such as Qatar, UAE, Lebanon, and India, and is higher than in Indonesia, North Korea, Maldives, and Nepal (19). The overall prevalence of developmental disorders, considering people with problems in more than one area as one person, was 3.5\%. The prevalence of developmental delay was $13.4 \%$ in infants in Gonabad, Iran (20) and $2.5 \%$ in under two-year-old children in India (21).

In this study, there was no relationship between the mother's depression and developmental disabilities in infants. This finding is somewhat consistent with Turner's study that indicated depression during pregnancy and the first two months after child delivery, regardless of the severity of symptoms, has no relationship with developing insecure attachment in 14-month-old children (13). However, Black's study showed that the mother's depression was associated with developmental motor disabilities (11). Sliwerski, in a systematic review showed that maternal depression affects infant attachment, and stated that this re- lationship is both complex and dynamic (22). Barnes and Theule meta-analyzed the results of 42 articles on the relationship between mother's depression and insecure attachment in children under one year of age, and revealed that insecure attachment is two times more in children of depressed mothers than in children of healthy mothers (23). Behrendt states that the mother's sensitivity to the needs of the child and her relationship with the child after infancy, which can be affected by the mother's clinical depression, can negatively affect the early socioemotional development of children of 12 to 16 months (24).

In this study, the mother's age was significantly related to communication and personal-social skills in infants. However, in Ghana, researchers did not find a significant relationship between the mother's age and any of the developmental areas of the child (25). Chittleborough related only $3 \%$ of child developmental disabilities to the young age of mothers (26), and Turley, by controlling for the family support factor in young mothers, showed that mother's age had no significant relationship with developmental disabilities in children (27). However, a study in the United States, which assessed the impact of social and demographic risk factors on the incidence of mental retardation, stated that a mother's age is one of the factors associated with child mental retardation (28).

While our study did not show any relationship between mother's education and the incidence of developmental disabilities in children, a study in the United States considered mother's low education at birth (less than 12 years of educations) as the strongest factor in the development of mental retardation at 10 years of age (29). Also, in the studies by Guo (30) and Rhum (31), mother's education was considered one of the influential factors on the incidence of developmental disabilities, and a study in Ghana associated mother's low education with the incidence of developmental disabilities in children in the domain of gross motor skills (25).

In the current study, no relationship was found between maternal employment outside the home and developmental disorders in infants. Rhum's study showed that a mother's employment in the first three years has little effect on the child's verbal abilities but can cause a significant decline in reading and math skills in children aged 5 - 6 years (31). The present study showed a significant correlation between the unfavorable economic situation and the occurrence of developmental disabilities in gross motor and problem-solving skills. This was also confirmed in Sameroff et al.'s study in which children who were at a socioeconomic risk were 24 times more likely to have an IQ below 85 compared to children in the low-risk group (32). 


\begin{tabular}{|c|c|c|c|c|c|c|}
\hline Variables & Communication & Gross Motor Skills & Fine Motor Skills & $\begin{array}{c}\text { Personal-Social } \\
\text { Skills }\end{array}$ & $\begin{array}{c}\text { Problem-Solving } \\
\text { Skills }\end{array}$ & Statistical Test \\
\hline Mother's depression & 0.18 & 0.65 & 0.23 & 0.22 & 0.09 & Independent $t$-test \\
\hline Mother's age & $0.034^{*}$ & 0.94 & 0.078 & $0.026^{*}$ & 0.43 & Pearson correlation \\
\hline Mother's education & 0.64 & 0.17 & 0.81 & 0.44 & 0.33 & Kruskal-Wallis \\
\hline $\begin{array}{l}\text { Socioeconomic } \\
\text { status }\end{array}$ & 0.79 & $0.012^{*}$ & 0.89 & 0.40 & $0.031^{*}$ & Kruskal-Wallis \\
\hline $\begin{array}{l}\text { Mother's } \\
\text { employment }\end{array}$ & 0.75 & 0.57 & 0.83 & 0.52 & 0.93 & Independent $t$-test \\
\hline
\end{tabular}

${ }^{\mathrm{a}}$ Significant items are determined by $\left({ }^{*}\right)$.

However, Carolyn in the United States, while stating the relationship between economic status and mental retardation, revealed that this correlation is not strong after controlling for mother's education (28).

\subsection{Conclusions}

The mother's depression is not related to the infant's developmental disorder. There is a significant relationship between the socioeconomic level of the family and gross motor and problem-solving skills of the infant, and the mother's age is directly related to communication and personal-social skills of the infant.

\section{Footnotes}

Authors' Contribution: Study concept and design, N.M.P.; Analysis and interpretation of data, F.E.; Drafting of the manuscript, N.M.P.; Critical revision of the manuscript for important intellectual content, N.M.P.; Statistical analysis, A.M.

Conflict of Interests: Authors mention that there is no conflict of interest in this study.

Funding/Support: This study was not funded by any organization.

\section{References}

1. Sajedi F, Ahmadi Doulabi M, Vameghi RBA, Mazaheri MZ. Development of children in Iran: a systematic review and meta-analysis. Glob J Health Sci. 2016;8(8):145-61. doi: 10.5539/gjhs.v8n8p145. [PubMed: 27045395]. [PubMed Central: PMC5016360].

2. Raymond C, Baker MD. Pediatric primary care: well-child care (Core Handbook Series in Pediatrics). Philadelphia, USA: Lippincott Williams \& Wilkins; 2001.

3. Grantham-McGregor S, Cheung YB, Cueto S, Glewwe P, Richter L, Strupp B. Developmental potential in the first 5 years for children in developing countries. The Lancet. 2007;369(9555):60-70. doi: 10.1016/s0140-6736(07)60032-4. [PubMed: 17208643]. [PubMed Central: PMC2270351]
4. Glascoe FP. Early detection of developmental and behavioral problems. Pediatr Rev. 2000;21(8):272-9. quiz 280. doi: 10.1542/pir.21-8-272. [PubMed: 10922024]

5. Abri S, Hajyousefi A, Hajbabayi H, Rahgozar M. [Comparison of social development between 3-6 years old children who use rural child care center services and who don't]. Soc Welf. 2011;11(41):343-68. Persian.

6. Persha A, Arya S, Nagar R, Behera P, Verma R, Kishore M. Biological and psychosocial predictors of developmental delay in persons with intellectual disability: retrospective case-file study. Actionaid Disabil News. 2007;18(1):93-100.

7. de Moura DR, Costa JC, Santos IS, Barros AJ, Matijasevich A, Halpern R et al. Risk factors for suspected developmental delay at age 2 years in a Brazilian birth cohort. Paediatr Perinat Epidemiol. 2010;24(3):211-21. doi: 10.1111/j.1365-3016.2010.01115.x. [PubMed: 20415750]. [PubMed Central: PMC3500503].

8. Irwin L, Siddiqi A, Hertzman C. Early child development: A powerful equalizer. Final report for the World Health Organization's Commission on the social determinants of health. Geneva, Switzerland: World Health Organization; 2007.

9. Van Batenbary Eddesa T, de Groot L, Huizink AC, Steegers EA, Hofman A, Jaddoe VW, et al. Maternal symptoms of anxiety during pregnancy affect infant neuromotor development: the generation R study. Dev Neuropsychol. 2009;34(4):476-93. doi: 10.1080/87565640902964508. [PubMed: 20183712].

10. Coyl DD, Roggman LA, Newland LA. Stress, maternal depression, and negative mother-infant interactions in relation to infant attachment. Infant Ment Health J. 2002;23(1-2):145-63. doi:10.1002/imhj.10009.

11. Black MM, Baqui AH, Zaman K, McNary SW, Le K, Arifeen SE, et al. Depressive symptoms among rural Bangladeshi mothers: implications for infant development. J Child Psychol Psychiatry. 2007;48(8):764-72. doi: 10.1111/j.1469-7610.2007.01752.x. [PubMed: 17683448].

12. Fathiashtiani A. [Psychological tests: personality and mental health] Tehran, Iran: Be'sat Publication; 2009. Persian.

13. Tharner A, Luijk MP, van Ijzendoorn MH, Bakermans-Kranenburg MJ, Jaddoe VW, Hofman A, et al. Maternal lifetime history of depression and depressive symptoms in the prenatal and early postnatal period do not predict infant-mother attachment quality in a large, population-based Dutch cohort study. Attach Hum Dev. 2012;14(1):6381. doi: 10.1080/14616734.2012.636659. [PubMed: 22191607].

14. Thompson LA, Tuli SY, Saliba H, DiPietro M, Nackashi JA. Improving developmental screening in pediatric resident education. Clin Pediatr (Phila). 2010;49(8):737-42. doi: 10.1177/0009922810363818. [PubMed: 20356921].

15. Molagh ME. [Executive instructions for the child developmental intervention program]. Gonabad, Iran: Ministry of Health; 2012. Persian. Available from: http://www.gmu.ac.ir/Dorsapax/userfiles/file/ fileGum/images/m-behdashti/khanevadeh/moraghebat_momtad_ takamol.pdf. 
16. Kaviani H, Nazari H, Hormozi K; Ahmadi Abhari. [Prevalence of depressive disordrs in Tehran resident population]. Tehran Univ Med J. 2000;60(5):393-9. Persian.

17. Modabernia MJ, Tehrani HS, Fallahi M, Shirazi M, Modabbernia AH Prevalence of depressive disorders in Rasht, Iran: A community based study. Clin Pract Epidemiol Ment Health. 2008;4:20. doi: 10.1186/17450179-4-20. [PubMed: 18601715]. [PubMed Central: PMC2481263].

18. GBD 2016 Disease and Injury Incidence and Prevalence Collaborators. Global, regional, and national incidence, prevalence, and years lived with disability for 328 diseases and injuries for 195 countries, 19902016: A systematic analysis for the Global Burden of Disease Study 2016. Lancet. 2017;390(10100):1211-59. doi:10.1016/S0140-6736(17)321542. [PubMed: 28919117]. [PubMed Central: PMC5605509].

19. Federici S, Bracalenti M, Meloni F, Luciano JV. World Health Organization disability assessment schedule 2.0: An international systematic review. Disabil Rehabil. 2017;39(23):2347-80. doi: 10.1080/09638288.2016.1223177. [PubMed: 27820966].

20. Tavakolizade J; Ghahremani. [Evaluation of developmental indicators of one-year-old children in Gonabad city and its comparison with standard criteria]. Iran J Pediatr. 1381;13(Suppl). Persian.

21. Poon JK, LaRosa AC, Pai GS. Developmental delay timely identification and assessment. Indian Pediatr. 2010;47(5):415-22. doi: 10.1007/s13312010-0077-3. [PubMed: 20519787].

22. Sliwerski A, Kossakowska K, Jarecka K, Switalska J, BielawskaBatorowicz E. The Effect of Maternal Depression on Infant Attachment: A Systematic Review. Int I Environ Res Public Health. 2020;17(8). doi: 10.3390/ijerph17082675. [PubMed: 32295106]. [PubMed Central: PMC7216154].

23. Barnes J, Theule J. Maternal depression and infant attachment security: A meta-analysis. Infant Ment Health J. 2019;40(6):817-34. doi: 10.1002/imhj.21812. [PubMed: 31415711]
24. Behrendt HF, Scharke W, Herpertz-Dahlmann B, Konrad K, Firk C. Like mother, like child? Maternal determinants of children's early socialemotional development. Infant Ment Health J. 2019;40(2):234-47. doi: 10.1002/imhj.21765. [PubMed:30731022].

25. Bello AI, Quartey JN, Appiah LA. Screening for developmental delay among children attending a rural community welfare clinic in Ghana. BMC Pediatr. 2013;13:119. doi: 10.1186/1471-2431-13-119. [PubMed: 23937954]. [PubMed Central: PMC3751115].

26. Chittleborough CR, Lawlor DA, Lynch JW. Young maternal age and poor child development: predictive validity from a birth cohort. Pediatrics. 2011;127(6):e1436-44. doi: 10.1542/peds.2010-3222. [PubMed: 21536608].

27. Turley RN. Are children of young mothers disadvantaged because of their mother's age or family background? Child Dev. 2003;74(2):46574. doi: 10.1111/1467-8624.7402010. [PubMed: 12705567].

28. Drews CD, Yeargin-Allsopp M, Decoufle P, Murphy CC. Variation in the influence of selected sociodemographic risk factors for mental retardation. Am J Public Health.1995;85(3):329-34. doi:10.2105/ajph.85.3.329. [PubMed: 7892914]. [PubMed Central: PMC1614863].

29. Burack JA, Hodapp RM, Zigler E. Issues in the classification of mental retardation: differentiating among organic etiologies.J Child Psychol Psychiatry. 1988;29(6):765-79. doi: 10.1111/j.1469-7610.1988.tb00752.x. [PubMed: 2976769].

30. Guo G, Harris KM. The mechanisms mediating the effects of poverty on children's intellectual development. Demography. 2000;37(4):43147. doi: 10.1353/dem.2000.0005. [PubMed: 11086569].

31. Ruhm CJ. Parental employment and child cognitive development. J Human Resources. 2004;39(1):155-92. doi: 10.3368/jhr.XXXIX.1.155.

32. Sameroff AJ, Seifer R, Barocas R, Zax M, Greenspan S. Intelligence quotient scores of 4-year-old children: Social-environmental risk factors. Pediatrics. 1987;79(3):343-50. [PubMed: 3822634] 